\title{
Self-Efficacy and Professional Identity Among Freshmen Nursing Students: A Latent Profile and Moderated Mediation Analysis
}

\author{
Xiao Xiao Meit, Hui Yuan Wang, Xiao Na Wu, Jie Yi Wu, Ying Zi Lu and Zeng Jie Ye* \\ School of Nursing, Guangzhou University of Chinese Medicine, Guangzhou, China
}

This study was designed to estimate the associations between self-efficacy and professional identity. A total of 1,051 freshmen nursing students (FNSs) from the Be Resilient to Nursing Career (BRNC) program were recruited from four universities between September and November 2020. A latent profile and moderated meditation analysis were performed. Four profiles of self-efficacy were identified and named as Lowest (15.6\%), Med-low (45.0\%), Med-high (32.7\%), and Highest (6.7\%). The mediating role of resilience and the moderating effect of role models were also identified. Therefore, self-efficacy, resilience, and role models may be three important factors to professional identity in FNSs and these relationships should be further validated in longitudinal or interventional studies.

Hebei Institute of Physical E

Keywords: self-efficacy, resilience, professional identity, moderated mediation analysis, latent profile analysis, freshmen nursing students

Anni Wang,

Fudan University, China

Yilei Wang,

Qufu Normal University, China

\section{INTRODUCTION}

*Correspondence:

Zeng Jie Ye

zengjieye@qq.com

tORCID:

Xiao Xiao Mei

orcid.org/0000-0003-2721-5784

The shortage of nurses has become a global issue and nursing students' retention deserves additional attention from nursing scientists (Bakker et al., 2018; World Health Organization, 2020). Professional identity, defined as one's view about professional attributes, beliefs, values, motive, and experience (Slay and Smith, 2010), is developed to increase the retention rate which has been confirmed as a key predictor for nurses' retention (Guo et al., 2018; Wu et al., 2019). Ohlen and Segesten (1998) divide nurses' professional identity into three dimensions: personal (personal confidence), interpersonal (interaction between nurses and other nurses, forming professional identity from nursing skills and knowledge), and social history (understanding nurses' professional identity with social history). Professional identity develops through their understanding of the intended professional skills, qualities, conduct, culture, and ideology about nursing (Jackson, 2016; Browne et al., 2018). In addition, professional identity is positively associated with students' mental health, clinical performance, and care quality (Hensel and Laux, 2014; Sun et al., 2016; Nyirenda and Mukwato, 2017; Wang et al., 2019). Thus, the methods of improving professional identity resulting in a high retention rate should be further explained, and intervention programs designed to improve freshman nursing students' (FNS) professional identity may be cost-effective.

Self-efficacy, defined as people's self-confidence in facing great challenges and breaking through the difficulties, may directly affect one's professional identity (Bandura, 1997; Xiong et al., 2020). Low self-efficacy may cause burnout and low job satisfaction (Bulfone et al., 2016; Yao et al., 2018), resulting in a low professional identity level (Ren et al., 2021). Furthermore, self-efficacy was positively correlated with professional identity in the previous studies (Qiu et al., 2019; Shen et al., 2020). 
In addition, self-efficacy plays a significant role in fostering resilience (Kumfer, 1999; Cody, 2013; Rees et al., 2015), which has been confirmed as the strongest predictor of professional identity (Bhattarai et al., 2020; Zhang et al., 2021). However, no empirical study has examined the mediating role of resilience in the relationship between self-efficacy and professional identity (Hayat et al., 2021; Ma et al., 2021). Lastly, role models play an important role in the development of professional identity in FNS (Paice, 2002; Sternszus et al., 2020). Role models show more possibilities and values of the nursing profession through their own career development, so as to enhance FNSs' professional identity (Morgenroth et al., 2015; Wang, 2019). Thus, this variable should be further explained.

To be brief, self-efficacy, resilience, and role models have been confirmed as potential factors to professional identity (Chen et al., 2020; Lyu et al., 2020; Sternszus et al., 2020) while the associations between self-efficacy, resilience, role models, and professional identity combined in one equation have not been fully explained. The current study was designed to fill the gap, including the mediation effects of resilience and the moderation effect of role models. Based on previous studies, we hypothesized that (Figure 1A):

H1: Self-efficacy would be a significant predictor of professional identity.

H2: Several distinct self-efficacy patterns would be identified by Latent Profile Analysis (LPA).

H3: Resilience may play a mediating role between selfefficacy and professional identity.

H4: Role models may play a moderate role in the resilienceprofessional identity linkage.

\section{MATERIALS AND METHODS}

\section{Participants}

A total of 1,220 FNSs from four universities in Guangdong Province and Shandong Province were enrolled between September and November 2020. The inclusion criteria were as follows: (1) newly enrolled nursing students in 2020; (2) could communicate fluently in Mandarin; (3) willing to participate in this study. The exclusion criteria were: (1) had a diagnosis of mental disorders. All participants were approached by a researcher who verbally explained the purpose and procedure, and informed consent was obtained. Then, the instruments were administered and collected. The required minimum sample size was calculated, using the Power Analysis and Sample Size Software (PASS, version 15.0) (NCSS, LLC. Kaysville, UT, United States), with the confidence level of $95 \%$, the distance from mean to limit of 1.5, and an SD of 15 (Bujang and Adnan, 2016). The minimum sample size required was 482 with a $20 \%$ dropout rate.

\section{Instruments}

\section{Demographics}

Based on previous literature (Mussi et al., 2019; Xie et al., 2020), we collected the FNSs' demographic (age, gender, educational backgrounds, place of residence) and professionrelated information (do you have a nursing role model, are there any medical staffs as relatives).

\section{Self-Efficacy}

The General Self-efficacy Scale (GSES) was developed by Zhang and Schwarzer (1995), and the Chinese version has been proved to be reliable (Wang et al., 2001; Zhang et al., 2018). It has 10 items and was a 4-point-Likert scale ranging from 10 to 40 . The scale is divided into three levels: low (10-20 points), medium (21-30 points), and high (31-40 points). The Cronbach's alpha for GSES was 0.900 .

\section{Resilience}

The Connor-Davidson Resilience Scale (CD-RISC) was developed by Connor in 2003, which consisted of 25 items (Connor and Davidson, 2003). A 10-item unidimensional version was later developed by Campbell-Sills and Stein (Campbell-Sills and Stein, 2007). It was a 5-Likert scale (0-4) with high scores indicating high resilience levels. The Chinese version of CD-RISC-10 has been approved to be reliable (Ye et al., 2017). The Cronbach's alpha coefficient for CD-RISC-10 in this study was 0.874 .

\section{Professional Identity}

The Chinese Version of the Professional Identity Questionnaire for Undergraduate Students (PIQUS) was developed by Qin (Qin, 2009). PIQUS has 23 items and includes four dimensions: cognitive identity, emotional identity, behavioral identity, and fit identity. It is a 5-Likert scale (1-5) with high scores indicating a high level of professional identity. In this study, the Cronbach's alpha coefficients are 0.854 for cognitive identity, 0.914 for emotional identity, 0.855 for behavioral identity, and 0.858 for fit identity.

\section{Data Analysis}

First, descriptive analysis was used to describe the demographics and profession-related characteristics. In addition, Pearson's correlation analysis was employed to determine the relationships among self-efficacy, resilience, and professional identity.

Second, LPA was performed to recognize the latent subgroups of FNSs' self-efficacy. It began with a one-class model, continuing until fit indices could not be improved. For determining the number of latent groups, Akaike Information Criterion (AIC) (Simpson et al., 2018), Bayesian Information Criterion (BIC) (Coulombe et al., 2016), and sample size-adjusted BIC (ssaBIC) (Sclove, 1987) were utilized as indicators. The Lo-MendellRubin likelihood ratio test (LMRT) and the bootstrapped likelihood ratio test (BLRT) (Lo et al., 2001) were used to test whether the introduction of one more category (i.e., latent group) contributed to a significant change compared to the previously derived model. ANOVA was applied to compare the professional identity among the FNSs with different self-efficacy profiles.

Third, Harman's one-factor model was performed to verify the potential existence of the common method variance (CMV). The mediator role of resilience was first estimated between LPAbased self-efficacy profiles (category variable) and professional identity (including four domains) through the PROCESS macro 


\section{A The conceptual model}

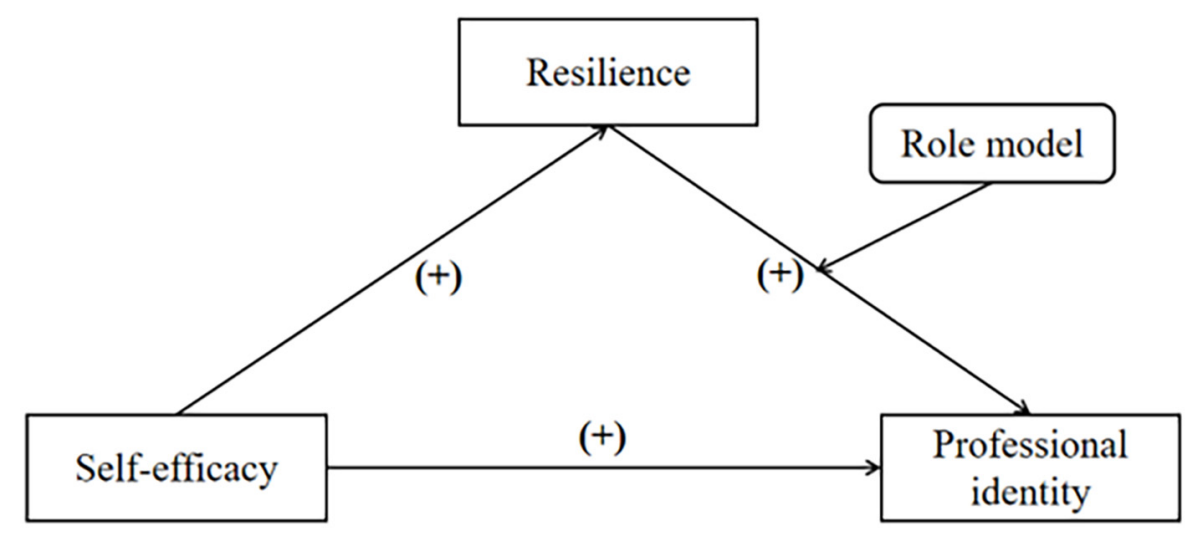

B Demographic and professional characteristic differences in scores of professional identity

\begin{tabular}{llll}
\hline Characteristics & $N(\%)$ & $\begin{array}{l}\text { Professional identity mean } \\
( \pm \text { SD })\end{array}$ & $P$ value \\
\hline $\begin{array}{l}\text { Gender } \\
\text { Male }\end{array}$ & 216 & $83.29 \pm 14.42$ & 0.074 \\
\hline Female & 835 & $85.22 \pm 14.13$ & \\
\hline Education level & & & 0.055 \\
\hline Junior college education & 472 & $85.76 \pm 14.77$ & \\
\hline Bachelor education & 579 & $84.06 \pm 13.69$ & 0.820 \\
\hline Only children & & & 0.982 \\
\hline Yes & 178 & $85.04 \pm 14.28$ & \\
\hline No & 873 & $84.78 \pm 14.19$ & 0.001 \\
\hline Residence & & & \\
\hline Countryside & 676 & $84.82 \pm 14.21$ & \\
\hline Cities or towns & 375 & $84.84 \pm 14.20$ & 0.000 \\
\hline Are there any medical staffs as relatives & & & \\
\hline Yes & 308 & $87.00 \pm 14.90$ & 0.000 \\
\hline No & 743 & $83.92 \pm 13.18$ & \\
\hline Do you have nursing role model & & & \\
\hline Yes & 418 & $89.38 \pm 13.96$ & \\
\hline No & 633 & $81.82 \pm 13.55$ & \\
\hline Do you want to leave the profession & & $75.24 \pm 12.64$ & \\
\hline Yes & 318 & $88.98 \pm 13.76$ & \\
\hline No & 733 & & \\
\hline
\end{tabular}

FIGURE 1 | (A) The Conceptual model. (B) Demographic and professional characteristic differences in scores of professional identity.

(Model 4) of SPSS (IBM Corp., Armonk, NY, United States). Subsequently, resilience was enrolled into the regressions between self-efficacy (continuous variable) and professional identity and the effect of the role model was fully explained by PROCESS macro (Model 58). To be brief, self-efficacy was the independent variable $(\mathrm{X})$, four domains of professional identity were the dependent variables $(\mathrm{Y})$, resilience was the mediator, and role model was the moderated variable. The total, direct and indirect effects were estimated and the mediating effect was considered statistically significant if the $95 \%$ bootstrap confidence interval did not contain zero (Hayes, 2017). SPSS
(IBM Corp., Armonk, NY, United States) (version 26.0) and Mplus (Muthén and Muthén, 2000) (version 8.3) were used for all statistical analyses.

\section{RESULTS}

\section{Sample Characteristics}

A total of 1,220 FNSs were invited to participate in the survey but 169 participants were excluded because they refused to complete the survey $(N=93)$ or had missing data $(N=76)$. No significant 
demographic difference was identified between the included and the excluded $(P>0.05)$. The sex ratio of males to females was 1:3.87. In total, $54.8 \%$ FNSs had a bachelor education level and $64.3 \%$ FNSs were from the countryside. In this study, the mean score of professional identity was $84.82 \pm 14.20$. Significant differences of professional identity were identified in variables, including: are there any medical staff as relatives $(P=0.001)$, do you have a nursing role model $(P<0.001)$, do you want to leave the profession $(P<0.001)$. Other details were summarized in Figure 1B.

\section{Latent Profile Analysis of Self-Efficacy}

In Figure 2A, LMRT indicated that a three-profile model was better than a two-profile one $(P=0.0053)$, and a fourprofile model is better than a three-profile one $(P=0.0232)$ while the difference between a four-profile model and a fiveprofile one was not significant $(P=0.1311)$. Thus, according to the parsimonious guideline, we finally chose the four-profile solution. The subgroups were named as Lowest (15.6\%), Med-low (45.0\%), Med-high (32.7\%), and Highest (6.7\%) groups and other information was summarized in Figure 2B. The professional identity levels in different self-efficacy profiles were presented in Figure 2C.

\section{Meditation Analysis of Resilience Between Self-Efficacy Profiles (Category Variable) and Professional Identity}

The variance explained by the first factor was $30.3 \%$ and did not reach $50 \%$, so the common method bias was controllable. The professional identity, GSES, and CD-RISC-10 were 84.82 (SD, 14.20), 23.78 (SD, 5.42), and 24.87 (SD, 5.91), respectively. Furthermore, professional identity was significantly correlated with self-efficacy $(r=0.376, P<0.01)$ and resilience $(r=0.404$, $P<0.01)$. Other information was summarized in Figure 3A. In Figure 3B, taking Profile 1 as the reference, the mediating effect of resilience between profile 2 , profile 3 , profile 4 , and cognitive identity were $0.144,0.300$, and 0.470 , respectively, with $95 \%$ Bootstrap confidence intervals of $(0.09,0.21),(0.19,0.42),(0.29$, $0.66)$, excluding " 0 ," indicating a significant mediating effect. Similar findings were identified in domains of emotional identity, behavioral identity, and fit identity in Figure 3B, indicating that resilience did play a mediating role between self-efficacy profiles and professional identity.

\section{Meditation Analysis of Resilience Between Self-Efficacy (Continuous Variable) and Professional Identity}

Professional identity varied significantly on three demographic variables and these three variables were dummy coded and assigned as covariates in the regressions.

In Figure 3C, the significant total effect of self-efficacy were identified on all domains of professional identity, including: cognitive identity $(B=0.165, S E=0.017, P<0.001)$, emotional identity $(B=0.275, S E=0.029, P<0.001)$, behavioral identity $(B=0.286, S E=0.022, P<0.001)$, and fit identity $(B=0.219$, $S E=0.016, P<0.001)$. In Figure $3 \mathrm{D}$, the significant mediation effect of resilience from self-efficacy to professional identity were also recognized, including: cognitive identity $(B=0.073$, SEBoot $=0.017,95 \%$ CI:0.04, 0.11), emotional identity $(B=0.131$, SEBoot $=0.025,95 \%$ CI:0.08, 0.18), behavioral identity $(B=0.106$, SEBoot $=0.020,95 \% \mathrm{CI}: 0.07,0.15)$, and fit identity $(B=0.070$, SEBoot $=0.014,95 \%$ CI:0.04, 0.10).

\section{The Moderated Meditation Analysis Combing Resilience and Role Model}

In Figure 4A, the significant interaction between resilience and role model was recognized $(B=0.344, S E=0.120,95 \% \mathrm{CI}: 0.11$, $0.58, P<0.01)$, indicating that the relationship between resilience and professional identity was moderated by role models $\left(R^{2}=0.396, F=113.821, P<0.01\right)$. According to the simple slopes tests in Figure 4B, FNSs with role models $(B=0.766$, $S E=0.106,95 \%$ CI:0.56, 0.98, $t=7.201, P<0.001)$ will have more professional identity increment compared to those without role models $(B=0.422, S E=0.087,95 \% \mathrm{CI}: 0.25,0.60, t=4.834$, $P<0.001)$ when resilience was increased.

\section{DISCUSSION}

There existed heterogeneity in self-efficacy among FNSs and resilience could mediate the associations between self-efficacy and professional identity after controlling the effect of covariates. In other words, self-efficacy might promote individuals' resilience resulting in improved professional identity. In addition, role models might moderate the associations between resilience and professional identity.

First, in this study, self-efficacy was positively associated with professional identity, which was consistent with previous research (Qiu et al., 2019; Eren and Turkmen, 2020). In addition, LPA was utilized to identify latent profiles of self-efficacy among FNSs and yielded a four-profile solution, which was consistent with Newnham et al. (2017) research. What's more, both selfefficacy profiles (category variable) and self-efficacy (continuous variable) were significantly mediated by resilience in the current study, and how to enhance resilience resulting in higher levels of professional identity should be further explored. According to Stephens Model of Nursing Student Resilience (Stephens, 2013), as nursing students learn to identify, enhance, and/or develop their protective factors, they will be better equipped to effectively manage perceived adversity and stress. Cultivating resilience among nursing students may help with academic success, sustaining students' demands for the nursing profession, and increasing professional identity (Smith and Yang, 2017; Keener et al., 2021; Zhang et al., 2021). These findings suggested that it was feasible to incorporate intervention techniques targeting resilience into professional identity enhancement programs for FNSs with low self-efficacy (Morrish et al., 2017; Lopez et al., 2018). For example, Chow et al. (2020) incorporated a resiliencebuilding module into the undergraduate nursing curriculum for 195 nursing students and received a good response from the participants.

Second, role model was confirmed as a moderator between resilience and professional identity. In other words, the 


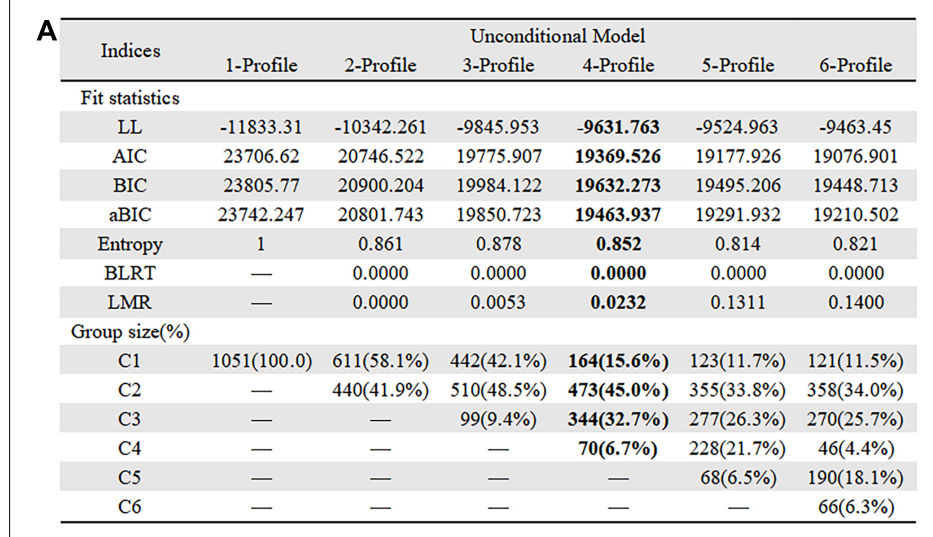

C

\begin{tabular}{lllllll}
\hline Subscales of GSES & MD 1 vs. 2 & MD 1 vs. 3 & MD 1 vs. 4 & MD 2 vs. 3 & MD 2 vs. 4 \\
\hline Cognitive identity & $-1.203(-2.01,-0.39)$ & $-2.221(-3.07,-1.37)$ & $-3.252(-4.53,-1.98)$ & $-1.019(-1.65,-0.39)$ & $-2.050(-3.19,-0.91)$ & $-1.031(-2.20,-0.14)$ \\
Emotional identity & $-1.808(-3.43,-0.19)$ & $-3.147(-4.84,-1.45)$ & $-6.376(-8.93,-3.83)$ & $-1.340(-2.61,-0.07)$ & $-4.568(-6.86,-2.28)$ & $-3.228(-5.57,-0.89)$ \\
\hline Behavioral identity & $-2.073(-3.10,-1.05)$ & $-3.526(-4.60,-2.45)$ & $-6.296(-7.91,-4.68)$ & $-1.453(-2.25,-0.65)$ & $-4.223(-5.67,-2.77)$ & $-2.770(-4.25,-1.29)$ \\
\hline Fit identity & $-6.914(-10.28,-3.55)$ & $-11.663(-15.19,-8.14)$ & $-20.943(-26.25,15.64)$ & $-4.748(-7.38,-2.11)$ & $-14.028(-18.79,-9.27)$ & $-9.280(-14.15,-4.41)$ \\
\hline
\end{tabular}

Comparison of professional identity between the FNSs with different levels self-efficacy

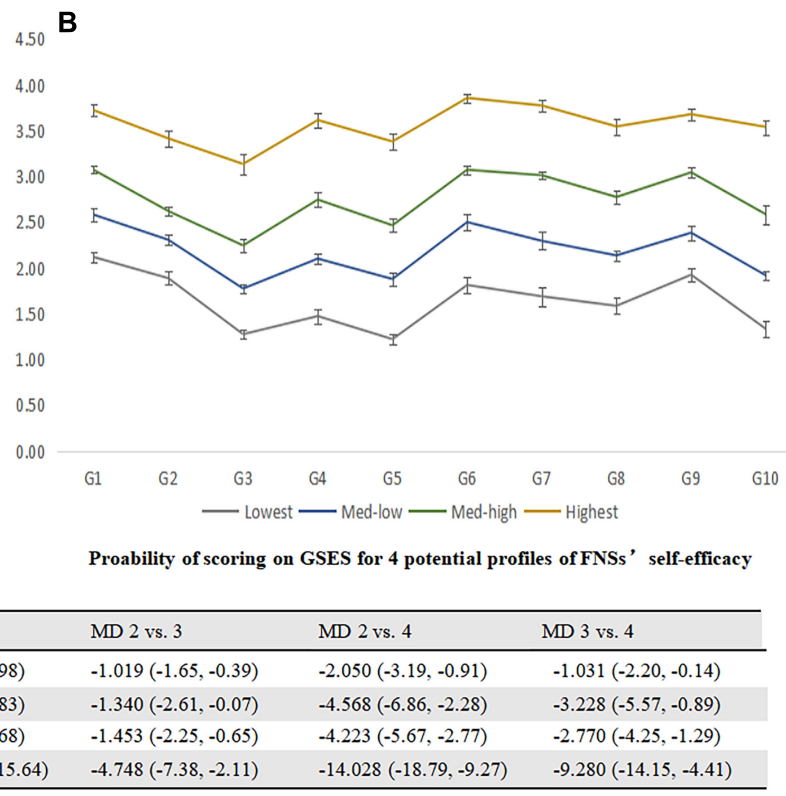

FIGURE 2 | (A) Fitting index and group size of latent profile analysis models. (B) Probability of scoring on GSES for 4 profiles of FNS's self-efficacy. (C) Comparison of professional identity between the FNSs with different levels self-efficacy.

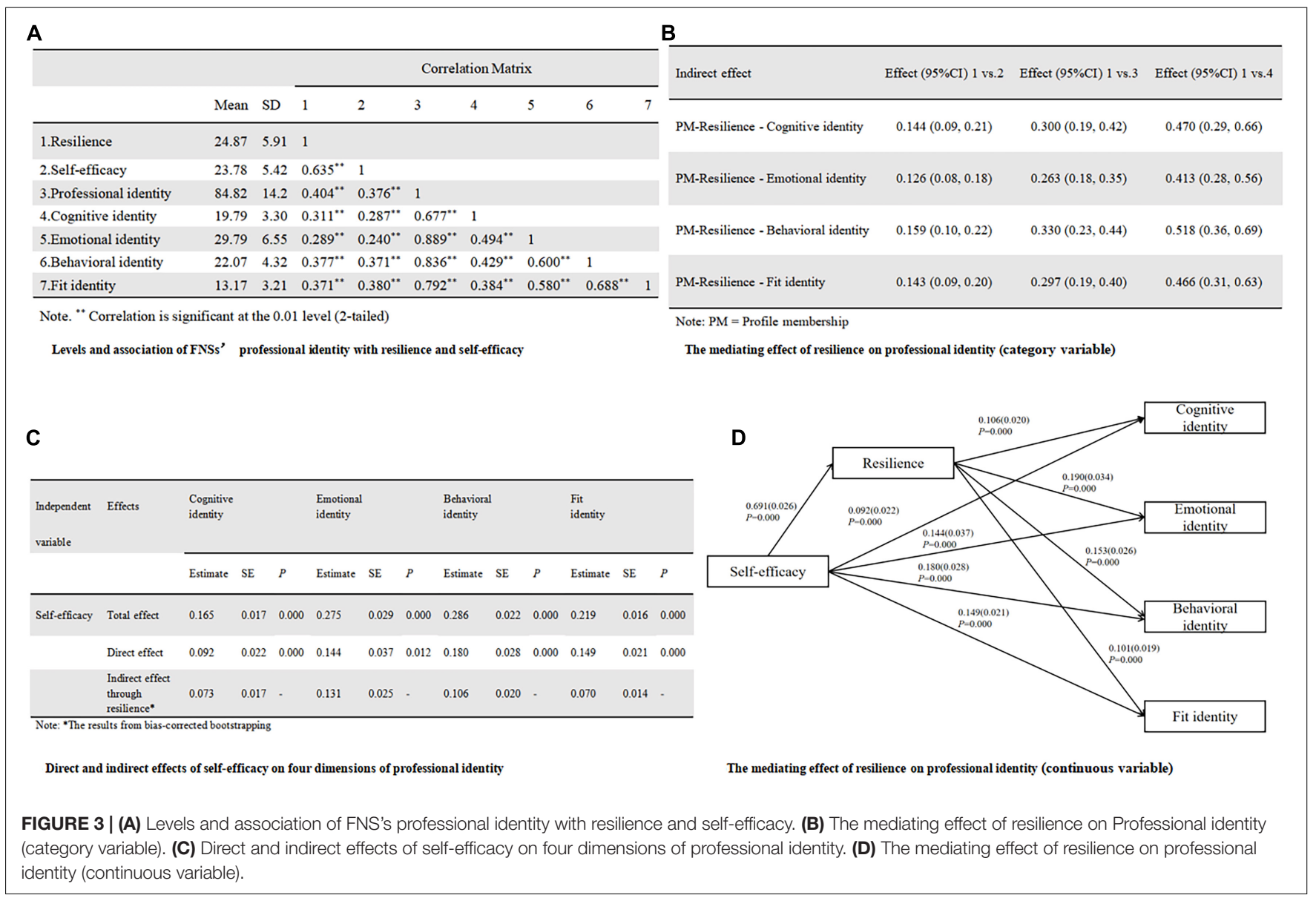




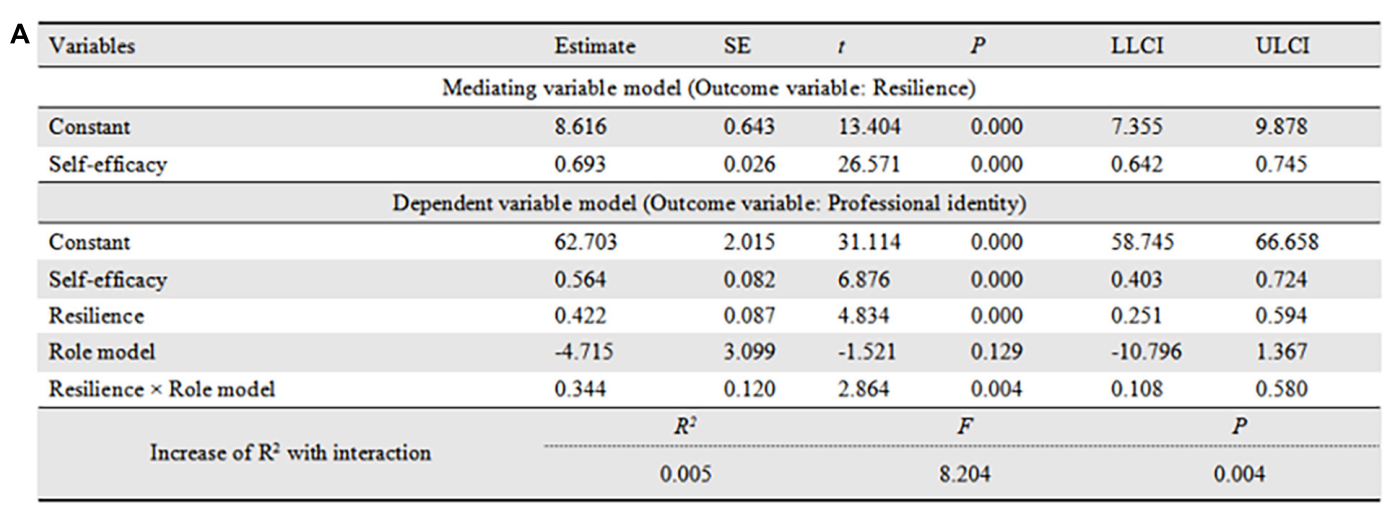

The moderated mediating effect of role model through resilience on self-efficacy and professional identity

B

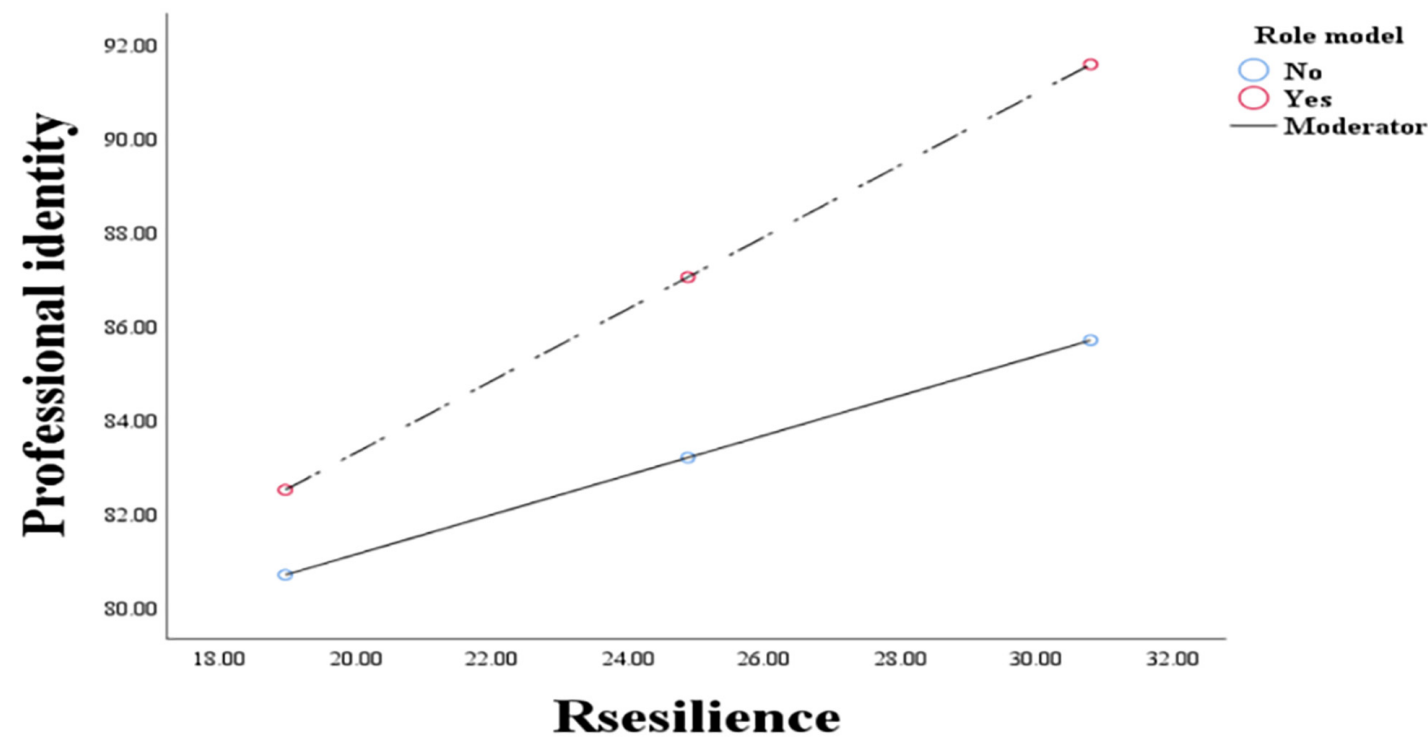

The interaction between resilience and role model on professional identity

FIGURE 4 | (A) The moderated mediating effect of role model through resilience on self-efficacy and professional identity. (B) The interaction between resilience and role model on professional identity.

correlations between resilience and professional identity were stronger in FNSs with role models compared to those without role models. Role models were critically important in the professional, character, and career development of the medical students (Passi and Johnson, 2016; Mohamed Osama and Gallagher, 2018). For example, undergraduate nursing students valued role models as beneficial to their learning (Jack et al., 2017). In addition, role models could motivate nursing students to change their prejudices about the nursing profession through imitative learning, and allow FNSs to see more possibilities in the nursing profession, which in turn amplified the positive effect of resilience on professional identity. Thus, role models could be incorporated to enhance professional identity.

To conclude, this study contributed to better understanding the associations between self-efficacy and resilience and role model and professional identity among FNSs. Our results showed that (1) professional identity could be increased by self-efficacy and resilience; (2) role models could enhance the strength between resilience and professional identity.

\section{LIMITATIONS}

Several limitations should be noted. First, the sample collected is based on Chinese FNSs, which may be different from western countries. Thus, the findings in the current study cannot be generalized to other FNSs with different backgrounds. Second, this study is cross-sectional and no causal relationships can be concluded. Longitudinal or interventional studies should be performed in the future to confirm these associations derived from the current study. Third, there still exists other factors affecting the professional identity, and more factors should be incorporated in future research with a more sophisticated method, for example, Structural Equation Model (SEM), which 
can take measurement bias into consideration and provide a more precise parameter estimation.

\section{CONCLUSION}

Self-efficacy, resilience, and role models may be three important factors to professional identity in FNSs and these relationships should be further validated in longitudinal or interventional studies.

\section{DATA AVAILABILITY STATEMENT}

The raw data supporting the conclusions of this article will be made available from the corresponding author by request.

\section{ETHICS STATEMENT}

The studies involving human participants were reviewed and approved by the Ethics Committee of The First Affiliated Hospital of Guangzhou University of Chinese Medicine [No: ZYYECERK(2020)132]. The patients/participants provided their written informed consent to participate in this study.

\section{REFERENCES}

Bakker, E. J. M., Kox, J. H. A. M., Miedema, H. S., Bierma-Zeinstra, S., Runhaar, J., Boot, C. R. L., et al. (2018). Physical and mental determinants of dropout and retention among nursing students: protocol of the SPRiNG cohort study. BMC Nurs. 17:27.doi: 10.1186/s12912-018-0296-9

Bandura, A. (1997). Self-Efficacy: The Exercise of Control[M]. New York, NY: W H Freeman.

Bhattarai, M., Jin, Y., Smedema, S. M., Cadel, K. R., and Baniya, M. (2020). The relationships among self-efficacy, social support, resilience, and subjective wellbeing in persons with spinal cord injuries. J. Adv. Nurs. 77, 221-230. doi: 10.1111/jan.14573

Browne, C., Wall, P., Batt, S., and Bennett, R. (2018). Understanding perceptions of nursing professional identity in students entering an Australian undergraduate nursing degree. Nurse Educ. Pract. 32, 90-96. doi: 10.1016/j.nepr.2018.07.006

Bujang, M. A., and Adnan, T. H. (2016). Requirements for minimum sample size for sensitivity and specificity analysis. J. Clin. Diagnostic Res. 10, YE01-YE06. doi: 10.7860/JCDR/2016/18129.8744

Bulfone, G., Fida, R., Ghezzi, V., Macale, L., Sili, A., Alvaro, R., et al. (2016). Nursing student self-efficacy in psychomotor skills. Nurse Educ. 41, E1-E6. doi: $10.1097 /$ nne.0000000000000285

Campbell-Sills, L., and Stein, M. B. (2007). Psychometric analysis and refinement of the connor-davidson resilience scale (CD-RISC): validation of a 10-item measure of resilience. J. Trauma. Stress 20, 1019-1028. doi: 10.1002/jts.20271

Chen, X., Zhong, J., Luo, M., and Lu, M. (2020). Academic self-efficacy. social support, and professional identity among preservice special education teachers in China. Front. Psychol. 11:374. doi: 10.3389/fpsyg.2020.00374

Chow, K. M., Tang, F. W. K., Tang, W. P. Y., and Leung, A. W. Y. (2020). Resilience-building module for undergraduate nursing students: a mixedmethods evaluation. Nurse Educ. Pract. 49:102912. doi: 10.1016/j.nepr.2020. 102912

Cody, J. A. (2013). The Roles of Stress Appraisal and Self-Efficacy in Fostering Resilience to Improve Psychosocial Outcomes Following Negative Life Events Among College Students: A Multiple Mediation Analysis. PhD diss, University of Tennessee. Available online at: https://trace.tennessee.edu/utk_graddiss/ 2409 (accessed July 10, 2021).

\section{AUTHOR CONTRIBUTIONS}

XM: conceptualization, data curation, methodology, software, and writing-original draft. HW: investigation, resources, software, and validation. XW: investigation, software, and methodology. JW and YL: investigation and resources. ZY: supervision and writing-review and editing. All authors contributed to the article and approved the submitted version.

\section{FUNDING}

The work was supported by the Humanities and Social Sciences Foundation of Guangzhou (Grant No. 2021GZGJ57) and the Humanities and Social Sciences Foundation of Guangzhou University of Chinese Medicine (Grant No. 2020SKXK01).

\section{ACKNOWLEDGMENTS}

We would like to thank the nurse directors from participating universities for supporting the data collection and all the participants for completing the surveys.

Connor, K. M., and Davidson, J. R. T. (2003). Development of a new resilience scale: the connor-davidson resilience scale (CD-RISC). Depress. Anxiety 18, 76-82. doi: $10.1002 /$ da. 10113

Coulombe, S., Radziszewski, S., Meunier, S., Provencher, H., Hudon, C., Roberge, P., et al. (2016). Profiles of recovery from mood and anxiety disorders: a person-centered exploration of people's engagement in self-management. Front. Psychol. 7:584. doi: 10.3389/fpsyg.2016.00584

Eren, H., and Turkmen, A. S. (2020). The relation between nursing students' levels of self-efficacy and caring nurse-patient interaction: a descriptive study. Contemp. Nurse 56, 185-198. doi: 10.1080/10376178.2020.1782763

Guo, Y., Yang, L., Ji, H., and Zhao, Q. (2018). Caring characters and professional identity among graduate nursing students in China-A cross sectional study. Nurse Educ. Today 65, 150-155. doi: 10.1016/j.nedt.2018.02.039

Hayat, A. A., Choupani, H., and Dehsorkhi, H. F. (2021). The mediating role of students' academic resilience in the relationship between self-efficacy and test anxiety. J. Educ. Health Promot. 31:297. doi: 10.4103/jehp.jehp_35_21

Hayes, A. F. (2017). Introduction To Mediation, Moderation, And Conditional Process Analysis: A Regression-Based Approach. New York, NY: Guilford publications.

Hensel, D., and Laux, M. (2014). Longitudinal study of stress, self-care, and professional identity among nursing students. Nurse Educ. 39, 227-231. doi: 10.1097/nne.0000000000000057

Jack, K., Hamshire, C., and Chambers, A. (2017). The influence of role models in undergraduate nurse education. J. Clin. Nurs. 26, 4707-4715. doi: 10.1111/jocn. 13822

Jackson, D. (2016). Re-conceptualising graduate employability: the importance of pre-professional identity. Higher Educ. Res. Dev. 35, 925-939. doi: 10.1080/ 07294360.2016.1139551

Keener, T. A., Hall, K., Wang, K., Hulsey, T., and Piamjariyakul, U. (2021). Quality of life, resilience, and related factors of nursing students during the COVID-19 pandemic. Nurse Educ. 46, 143-148. doi: 10.1097/NNE.0000000000000969

Kumfer, K. L. (1999). Factors and Processes Contributing To Resilience: The Resilience Framework [M]. New York, NY: Kluwer Academic.

Lo, Y. T., Mendell, N. R., and Rubin, D. B. (2001). Testing the number of components in a normal mixture. Biometrika 88, 767-778. doi: 10.1093/biomet/ 88.3.767 
Lopez, V., Yobas, P., Chow, Y. L., and Shorey, S. (2018). Does building resilience in undergraduate nursing students happen through clinical placements? A qualitative study. Nurse Educ. Today 67, 1-5. doi: 10.1016/j.nedt.2018.04.020

Lyu, H., Yao, M., Zhang, D., and Liu, X. (2020). The relationship among organizational identity, psychological resilience and work engagement of the first-line nurses in the prevention and control of COVID-19 based on structural equation model. Risk Manag. Healthc. Policy 13, 2379-2386. doi: 10.2147/ RMHP.S254928

Ma, R., Yang, F., Zhang, L., Sznajder, K. K., Zou, C., Jia, Y., et al. (2021). Resilience mediates the effect of self-efficacy on symptoms of prenatal anxiety among pregnant women: a nationwide smartphone cross-sectional study in China. BMC Pregnancy Childbirth 21:430. doi: 10.1186/s12884-021-03911-5

Mohamed Osama, O., and Gallagher, J. E. (2018). Role models and professional development in dentistry: an important resource: the views of early career stage dentists at one academic health science centre in England. Eur. J. Dent. Educ. 22, e81-e87. doi: 10.1111/eje.12261

Morgenroth, T., Ryan, M. K., and Peters, K. (2015). The motivational theory of role modeling: how role models influence role aspirants' goals. Rev. Gen. Psychol. 19, 465-483. doi: 10.1037/gpr0000059

Morrish, L., Rickard, N., Chin, T. C., and Vella-Brodrick, D. A. (2017). Emotion regulation in adolescent well-being and positive education. J. Happiness Stud. 19, 1543-1564. doi: 10.1007/s10902-017-9881-y

Mussi, F. C., Pires, C. G., da, S., Carneiro, L. S., Costa, A. L. S., Ribeiro, F. M. S. E. S., et al. (2019). Comparison of stress in freshman and senior nursing students. Rev. Esc. Enferm. USP 53:e03431. doi: 10.1590/s1980-220x2017023503431

Muthén, B., and Muthén, L. K. (2000). Integrating person-centered and variablecentered analyses: growth mixture modeling with latent trajectory classes. Alcohol. Clin. Exp. Res. 24, 882-891. doi: 10.1111/j.1530-0277.2000.tb02070.x

Newnham, E. A., Balsari, S., Lam, R. P. K., Kashyap, S., Pham, P., Chan, E. Y. Y., et al. (2017). Self-efficacy and barriers to disaster evacuation in Hong Kong. Int. J. Public Health 62, 1051-1058. doi: 10.1007/s00038-017-1036-8

Nyirenda, M., and Mukwato, P. (2017). Job satisfaction and attitudes towards nursing care among nurses working at Mzuzu Central Hospital in Mzuzu, Malawi. Malawi Med. J. 28:159. doi: 10.4314/mmj.v28i4.3

Ohlen, J., and Segesten, K. (1998). The professional identity of the nurse: concept analysis and development. J. Adv. Nurs. 28, 720-727. doi: 10.1046/j.1365-2648. 1998.00704.x

Paice, E. (2002). How important are role models in making good doctors? BMJ 325, 707-710. doi: 10.1136/bmj.325.7366.707

Passi, V., and Johnson, N. (2016). The impact of positive doctor role modeling. Med. Teach. 38, 1139-1145. doi: 10.3109/0142159x.2016.1170780

Qin, P. B. (2009). The Characteristics And Correlation Study Of College Students Specialty Identity [Chinese]. Master Thesis, Southwest University.

Qiu, T., Liu, C., Huang, H., Yang, S., Gu, Z., Tian, F., et al. (2019). The mediating role of psychological capital on the association between workplace violence and professional identity among Chinese doctors: a cross-sectional study. Psychol. Res. Behav. Manag. 12, 209-217. doi: 10.2147/prbm.s198443

Rees, C. S., Breen, L. J., Cusack, L., and Hegney, D. (2015). Understanding individual resilience in the workplace: the international collaboration of workforce resilience model. Front. Psychol. 6:37. doi: 10.3389/fpsyg.2015. 00073

Ren, Z., Zhang, X., Li, X., He, M., Shi, H., Zhao, H., et al. (2021). Relationships of organisational justice, psychological capital and professional identity with job burnout among Chinese nurses: a cross-sectional study. J. Clin. Nurs. 30, 2912-2923. doi: 10.1111/jocn.15797

Sclove, S. L. (1987). Application of model-selection criteria to some problems in multivariate analysis. Psychometrika 52, 333-343. doi: 10.1007/bf02294360

Shen, Y., Xie, W., Wang, X., Qu, J., Zhou, T., Li, Y., et al. (2020). Impact of innovative education on the professionalism of undergraduate nursing students in China. Nurse Educ. Today 98:104647. doi: 10.1016/j.nedt.2020.104647

Simpson, E. G., Vannucci, A., and Ohannessian, C. M. (2018). Family functioning and adolescent internalizing symptoms: a latent profile analysis. J. Adolesc. 64, 136-145. doi: 10.1016/j.adolescence.2018.02.004

Slay, H. S., and Smith, D. A. (2010). Professional identity construction: using narrative to understand the negotiation of professional and stigmatized cultural identities. Hum. Relat. 64, 85-107. doi: 10.1177/0018726710384290

Smith, G. D., and Yang, F. (2017). Stress, resilience and psychological well-being in Chinese undergraduate nursing students. Nurse Educ. Today 49, 90-95. doi: 10.1016/j.nedt.2016. 10.004

Stephens, T. M. (2013). Nursing student resilience: a concept clarification. Nurs. Forum 48, 125-133. doi: 10.1111/nuf.12015

Sternszus, R., Boudreau, J. D., Cruess, R. L., Cruess, S. R., Macdonald, M. E., and Steinert, Y. (2020). Clinical teachers' perceptions of their role in professional identity formation. Acad. Med. 95, 1594-1599. doi: 10.1097/acm. 0000000000003369

Sun, L., Gao, Y., Yang, J., Zang, X.-Y., and Wang, Y.-G. (2016). The impact of professional identity on role stress in nursing students: a cross-sectional study. Int. J. Nurs. Stud. 63, 1-8. doi: 10.1016/j.ijnurstu.2016.08.010

Wang, C., Hu, Z., and Liu, Y. (2001). Reliability and validity of general self-efficacy scale. Chinese J. Appl. Psychol. 7, 37-40.

Wang, L. (2019). Investigation and Analysis on the Professional Identity of Nursing Undergraduates in Anhui Province [Chinese]. Master thesis, Bengbu Medical College.

Wang, L., Yang, Y., Zhu, J., Xie, H., Jiang, C., Zhang, C., et al. (2019). Professional identity and mental health of rural-oriented tuition-waived medical students in Anhui Province. China. BMC Med. Educ. 19:199. doi: 10.1186/s12909-0191603-1

World Health Organization (2020). State of The World's Nursing 2020: Investing In Education, Jobs And Leadership. Geneva: World Health Organization.

Wu, C., Palmer, M. H., and Sha, K. (2019). Professional identity and its influencing factors of first-year post-associate degree baccalaureate nursing students: a cross-sectional study. Nurse Educ. Today 84:104227. doi: 10.1016/j.nedt.2019. 104227

Xie, J., Liu, M., Zhong, Z., Zhang, Q., Zhou, J., Wang, L., et al. (2020). Relationships among character strengths, self-efficacy, social support, depression, and psychological well-being in hospital nurses. Asian Nurs. Res. 14, 150-157. doi: 10.1016/j.anr.2020.06.002

Xiong, H., Yi, S., and Lin, Y. (2020). The psychological status and self-efficacy of nurses during COVID-19 outbreak: a cross-sectional survey. Inquiry 57:004695802095711. doi: 10.1177/0046958020957114

Yao, Y., Zhao, S., Gao, X., An, Z., Wang, S., Li, H., et al. (2018). General self-efficacy modifies the effect of stress on burnout in nurses with different personality types. BMC Health Serv. Res. 18:667. doi: 10.1186/s12913-018-3478-y

Ye, Z. J., Qiu, H. Z., Li, P. F., Chen, P., Liang, M. Z., Liu, M. L., et al. (2017). Validation and application of the Chinese version of the 10-item connor-davidson resilience scale (CD-RISC-10) among parents of children with cancer diagnosis. Eur. J. Oncol. Nurs. 27, 36-44. doi: 10.1016/j.ejon.2017. 01.004

Zhang, J. X., and Schwarzer, R. (1995). Measuring optimistic self-beliefs: a Chinese adaptation of the general self-efficacy scale. Psychologia 38, 174-181.

Zhang, X., Zhan, Y., Liu, J., Chai, S., Xu, L., Lei, M., et al. (2018). Chinese translation and psychometric testing of the cardiac self-efficacy scale in patients with coronary heart disease in mainland China. Health Qual. Life Outcomes 16:43. doi: 10.1186/s12955-018-0872-4

Zhang, Z., Fu, W., Tian, C., Zhang, F., Zhao, B., Mao, J., et al. (2021). Professional identity of Chinese nursing students during the COVID-19 pandemic outbreak: a nation-wide cross-sectional study. Nurse Educ. Pract. 52:103040. doi: 10.1016/ j.nepr.2021.103040

Conflict of Interest: The authors declare that the research was conducted in the absence of any commercial or financial relationships that could be construed as a potential conflict of interest.

Publisher's Note: All claims expressed in this article are solely those of the authors and do not necessarily represent those of their affiliated organizations, or those of the publisher, the editors and the reviewers. Any product that may be evaluated in this article, or claim that may be made by its manufacturer, is not guaranteed or endorsed by the publisher.

Copyright (c) $2022 \mathrm{Mei}$, Wang, Wu, Wu, Lu and Ye. This is an open-access article distributed under the terms of the Creative Commons Attribution License (CC BY). The use, distribution or reproduction in other forums is permitted, provided the original author(s) and the copyright owner(s) are credited and that the original publication in this journal is cited, in accordance with accepted academic practice. No use, distribution or reproduction is permitted which does not comply with these terms. 